\title{
ASSOCIAÇAO DOS SURDOS DE GOVERNADOR VALADARES, REDE SOCIAL FACEBOOK: RECORTE ANALITICO DO CAMINHAR NETNOGRAFICO E REPRESENTAÇOES SOCIAIS A ERIGIR A CIDADANIA COMUNICATIVA DOS SUJEITOS COMUNICANTES SURDOS
}

\section{Sonia Maria Queiroz de Oliveira ${ }^{1}$}

\section{Resumo}

Objetivamos analisar ações comunicacionais dos sujeitos surdos, as Representações Sociais dessas ações no Facebook Asugov $\mathrm{GV}^{2}$ e na Asugov ${ }^{3}$. Referencial teórico: TRS (Moscovici, 2007), Estudos Culturais (Strobel, 2018; Karnopp, Klein, Lunardi-Lazzarin, 2012), Netnografia (Kozinets, 2014). Abordagem transmetodológica (Maldonado, 2012). As referências para com a cultura surda são sinonímias das representações, sobre as quais o significado não se encontra no texto/relato, mas na relação entre o texto/relato e o contexto dos participantes, construto da cidadania comunicativa.

Palavras chaves: Sujeitos Comunicantes Surdos; Netnografia; Representações Sociais; Associação dos Surdos de Governador Valadares; Cidadania Comunicativa

\section{ASSOCIATION OF THE DEAF OF GOVERNADOR VALADARES, SOCIAL NETWORK FACEBOOK: ANALYTICAL CUT OF THE NETNOGRAPHIC WALK AND SOCIAL REPRESENTATIONS TO URGENT COMMUNICATIVE CITIZENSHIP OF DEAF COMMUNICATING SUBJECTS}

\begin{abstract}
We aim to analyze the communicational actions of deaf individuals, the Social Representations of these actions on Facebook Asugov GV and Asugov. Theoretical framework: TRS (Moscovici, 2007), Cultural Studies (Strobel, 2018; Karnopp, Klein, Lunardi-Lazzarin, 2012), Netnography (Kozinets, 2014). Transmethodological approach (Maldonado, 2012). References to deaf culture are synonymous with representations, about which the meaning is not found in the text / report, but in the relationship between the text / report and the participants' context, a construct of communicative citizenship.
\end{abstract}

Key words: Deaf Communicating Subject; Netnography; Social Representations; Deaf Association of Governador Valadares; Communicative Citizenship

\section{INTRODUÇAO}

\footnotetext{
${ }^{1}$ Doutoranda em Comunicação pelo Programa de Pós-graduação em Ciências da Comunicação da Universidade Vale do Rio dos Sinos (UNISINOS). Professora da Universidade Federal de Juiz de Fora-Campus GV (UFJF-GV). Email: oqms@hotmail.com; soniaqueiroz@ufjf.edu.br Lattes http://lattes.cnpq.br/6982131117793305._Orcid https://orcid.org/0000-0001-6070-4198.

2 O Facebook da Asugov $\mathrm{GV}^{2}$ é um perfil criado em 29 de junho de 2018. Disponível em: https://www.facebook.com/asugov.gv.9/about?lst=100002203802772\%3A100027118480161\%3A1570563621\& section=contact_basic

${ }^{3}$ Associação dos Surdos de Governador Valadares
} 
Sempre há necessidade de estarmos informados sobre o mundo à nossa volta. Além de nos ajustar a ele, precisamos saber como nos comportar, dominá-lo fisicamente ou intelectualmente, identificar e resolver os problemas que se apresentam: é por isso que criamos representações (JODELET, 2001, p.17).

Enveredar pelo caminho da pesquisa em comunicação com interface no Direito é fazer registrar, de partida, não acabamentos. Como a própria vida nos ensina em suas trajetórias, inacabadas, ensaiamos olhares no presente estudo, sobre ações comunicacionais dos sujeitos comunicantes surdos no ambiente digital Facebook Asugov $G^{4}$ e Associação dos Surdos de Governador Valadares (Asugov). O alcance observacional verticalizado nas estratégias discursivas objetiva analisar a constituição das Representações Sociais de Surdos pertencentes à Asugov e inscritos no ambiente social digital Facebook Asugov GV, sob aspectos da trajetória de suas vidas familiar, educacional, religiosa, comunitária, como contributo a erigir a cidadania comunicativa.

O presente artigo é um recorte da pesquisa empírica de doutoramento, ainda em realização (CAAE 22539819.7.0000.5344, Parecer CEP/Unisinos 3.637.504). O pressuposto epistemológico consubstanciador do processo de construção da empiria, elucubra-se na transmetodologia (MALDONADO, 2012), aos passos se uma abordagem netnográfica. Mesmo sendo a netnografia uma forma de pesquisa pós-modernista, amplamente aceita no campo de pesquisa da Teoria da Cultura do Consumo e Marketing, a trouxemos por sua ampla variedade de tópicos verticalizados em pesquisa social (Relações sociais) na internet, no Facebook Asugov GV, comunidade online social e continua. Para essa construção importante o é justificar a escolha dessa abordagem metodológica, pois a mesma possibilita uma olhar amplo, diversificado e qualificado sobre aquilo que o problema-objeto demanda (FOLETTO, 2011; KOZINETS, 2014).

Levando em consideração que as TICs $^{5}$ estão cada vez mais a enraizarem-se nas diversas áreas da vida social, neste dialogo ao qual nos propusemos, fazemos reforço com o argumento que através da flexibilidade e adaptabilidade do método etnográfico aos estudos culturais e comunidades online, significando conceber cultura(s) como teias de significados das vidas dos indivíduos participantes, guiadas por seus conjuntos de valores (familiar, educacional, religioso e comunitário), valores estes, os quais são alvo de interpretação e

\footnotetext{
${ }^{4}$ O Facebook da Asugov GV $\mathrm{G}^{4}$ é um perfil criado em 29 de junho de 2018. Disponível em: https://www.facebook.com/asugov.gv.9/about?lst=100002203802772\%3A100027118480161\%3A1570563621\&s ection=contact_basic

${ }^{5}$ Tecnologias de Informação e Comunicação
} 


\section{ASSOCIAÇAO DOS SURDOS DE GOVERNADOR VALADARES, REDE SOCIAL FACEBOOK: \\ RECORTE ANALITICO DO CAMINHAR NETNOGRAFICO E REPRESENTAÇOES SOCIAIS A ERIGIR A \\ CIDADANIA COMUNICATIVA DOS SUJEITOS COMUNICANTES SURDOS}

análise, materializado no conjunto do discurso interativo (Entrevistas), fonte de consulta a qualquer tempo (BRAGA, 2006; ROCHA, 2005, 2007), a materializar o exercício da cidadania comunicativa.

O estudo também abarca como referencial teórico a Teoria das Representações Sociais (TRS) (MOSCOVICI, 2007), dos Estudos Culturais pós-estruturalistas e dos Estudos Surdos (STROBEL, 2018 e KARNOPP, KLEIN, LUNARDI-LAZZARIN; 2012), em uma interface dialógica com a cidadania.

O corpus social da pesquisa e o corpus discursivo dos entrevistados foram os caminhos percorridos para a geração dos dados. Estes são filhos de pais ouvintes, em sua maioria, familiares ouvintes, apontando dificuldades em realização de comunicação entre os mesmos. Aprenderam a Libras em contato com amigos surdos, via de regra na Asugov. A maioria recebe 01 salário mínimo e assume profissões limitadas. Diante desses resultados se sustenta a tese de que as Representações Sociais dos Surdos sobre ser surdo em um mundo ouvinte são ruins. As objetivações, ou imagens dessas representações, foram reunidas em torno dos elementos correspondentes a dificuldade comunicacional entre familiares e da trajetória de vida dos mesmos. A rede social Facebook surge como meio comunicacional a erigir a cidadania comunicativa desse grupo populacional de maneira eficaz e efetiva.

\section{DESENVOLVIMENTO}

Os cientistas sociais chegam cada vez mais à conclusão de que não podem mais compreender adequadamente muitas das facetas mais importantes da vida social e cultural sem incorporar a internet e as comunicações mediadas por computador em seus estudos. (KOZINETS, 2014, p. 10/11).

Para compreensão e entendimento dos nossos caminhares em arenas netnograficas, apresentar os termos comunidade e cultura online relevante o é. Comunidade online, aos passos de Howard Rheingold (1993) citado por Kozinets (2014, p. 16) define-se como "agregações sociais que emergem da rede quando um número suficiente de pessoas empreende [...] discussões públicas por tempo suficiente, com suficiente sentimento humano, para formar redes de relacionamentos pessoais no ciberespaço" (KOZINETS, 204, P. 16). Destarte o termo 
comunidade online adequa-se ao grupo de pessoas pertencentes ao Facebook Asugov GV, como [...] "um grupo de pessoas que compartilham de interação social, laços sociais e um formato, localização ou "espaço" interacional comum, ainda que, nesse caso, um "ciberespaço" virtual ou mediado por computador" (KOZINET, 2014, p. 16).

Cultura e cibercultura online, sob perspectiva teórica do autor Raymond Wilhians (1967) apud Kozinet (2014, p. 17) é um conceito entrelaçado a própria civilização, socialização e aculturação. Com o tempo, antropologicamente tendeu-se a relacionar cultura à continuidade de comportamentos e valores; e aos sistemas simbólicos e idiomas através dos estudos culturais. Nesse sentido vale citar a observação registrada por Kozinet: "Em a Interpretação das Culturas (1973), o antropólogo Clifford Geertz sugeriu que a cultura pode ser mais bem compreendida do ponto de vista da semiótica ou dos significados de sinais e símbolos" (KOZINET, 2014, p. 17). Significados que comunicam tornando assim a cultura uma questão pública, de natureza coletiva relativa a um grupo. Nessa singularidade a qual nos apoiamos, o termo cibercultura adquire sua funcionabilidade, em conformidade ao pensar do autor Escobar (1994), nos seguintes dizeres: [...] "construções e reconstruções culturais singulares nas quais as novas tecnologias se baseiam e em que elas, inversamente, contribuem para moldar" (ESCOBAR, 1994 apud kozinet, 2014, p. 19). Optamos por adotar a terminologia cibercultura em conformidade à comunidade online Facebook Asugov GV, ao trabalho de uma escrita consciente assomada em seus sentidos.

\section{1- Passos netnograficos: como analisar a Rede Social Facebook Asugov GV}

Kozinet (2014, p. 52) ao citar Berkowitz (1982) e Willman (1988) apresenta a analise de rede social em sendo "um método analítico que focaliza as estruturas e os padrões de relacionamentos entre atores sociais em uma rede". Nesse sentido duas são as principais unidades de analise nas redes sociais: "nodos" conceito este que se referem aos atores sociais de uma rede, e, os "vínculos" que representam as relações estabelecidas entre esses atores sociais; composta do conjunto de atores ligados por um conjunto de laços relacionais.

Os "nodos" são o perfil do Facebook Asugov GV e os comunicantes surdos pertencentes à rede social Facebook Asugov GV e frequentes na Associação Asugov; 
conectados por relação social de amizade virtual, compartilhando informações por interesse comuns, e que aceitaram participar das entrevistas realizadas assinando o TCLE (Termo de Consentimento Livre e Esclarecido). Neste sentido oferta o pensamento Scott: [...] “Assim, a analise de redes sociais lida com dados relacionais e embora seja possível quantificar e analisar estatisticamente essas relações, a analise de rede "consiste em um corpo de mediadas qualitativas da estrutura de rede"”' (SCOTT, 1991 apud KOZINET, 2014, p. 53).

\section{2- Descritiva simplificada das etapas da pesquisa netnografica}

Para Kozinet (2014) devemos realizar e avaliar a netnografia em etapas. Essas perfazem sob formas de caminhares seis etapas, tais como: planejar o projeto de pesquisa e chegada ao campo de pesquisa; coletar e analisar os dados; lidar com os aspectos éticos; refletir sobre a construção realizada de maneira a equilibrar as relações de poder entre pesquisadora e pesquisados a alcançar o pensamento de que o etnógrafo deve fazer sua pesquisa e retornar com a mesma para a comunidade estudada. Nesse sentido construímos o fluxograma em conformidade ao objeto de estudo, sucintamente:

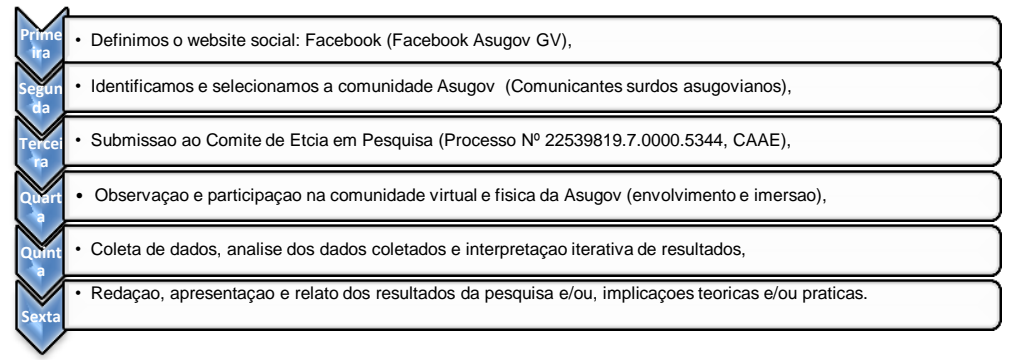

Inúmeras são as criticas apontadas por autores com respeito à pesquisa realizadas em ciberespaços. Entre essas aponto ausência de autenticidade e falsa neutralidade, por Novelli (2010) e Gilberto Velho (1997), por serem as mais recorrentes. Contrariamente, Pierre Levi vindo ao nosso socorro afirma:

O virtual não se opõe ao real, mas sim ao atual [...]. O virtual é como o complexo problemático, o nó de tendências ou de forças que acompanha uma situação, um acontecimento, um objeto ou uma entidade qualquer, e que chama um processo de resolução: a atualização (LEVI, 1996, p. 16). 
A escolha da rede social Facebook se deu porque a mesma cria, de certa forma, um convívio e sociabilidade entre seus associados conviventes na comunidade estabelecida. O local de pesquisa é protagonizado pelo Perfil Facebook Asugov GV. Os colaboradores da pesquisa foram os sujeitos comunicantes surdos, assíduos da Asugov e associados ao Facebook Asugov GV. Ao condão ético estabelecemos números de 02 a 13 para os entrevistados. O perfil Asugov GV é o numero 01 no grafo abaixo.

Figura 01: Grafo Rede Perfil Asugov GV e amigos

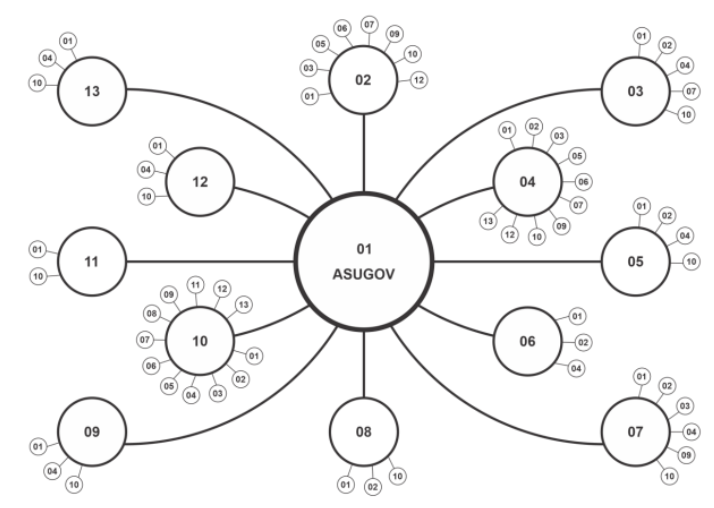

Fonte: Criação da autora

\section{3- Corpus social da pesquisa}

A comunidade Asugov registrou durante o ano de 2019 um universo de 50 surdos frequentes na associação, nas sextas e domingos, das $18 \mathrm{~h}$ às $22 \mathrm{~h}$. O presente artigo interliga-se a uma tese de doutoramento e, como critério estabelecido na pesquisa de campo daquela, aqui se recorta apenas no aceite em participação da pesquisa (questionamento oral, durante as reuniões da associação, por ocasião da apresentação da pesquisa e seus objetivos e convite à participação). Posteriormente, na associação, em sala climatizada, ao auxílio de intérprete habilitado, após apresentações de praxe e explicações das implicações em participar da pesquisa, foram realizadas as entrevistas, guiadas por um Roteiro Semiestruturado de Entrevistas. Este procedimento e instrumento de coleta de informações foram submetidos e aprovados pelo Comitê de Ética em Pesquisa (Processo No 22539819.7.0000.5344 - CAAE).

Dos 50 Sujeitos Comunicantes Surdos frequentes na Asugov, apenas 12 se dispuseram em participar da pesquisa. Conforme indicado no Quadro 01 abaixo, os participantes possuem em média 41,8 anos, sendo a maioria $(58 \%)$ do sexo feminino. Quanto à escolaridade $50 \%$ 
possui o Ensino Médio Completo, 34\% o Ensino Fundamental e 16\% o Ensino Superior. A renda média dos participantes é de 1,08 salários mínimos.

Quadro 01 - Entrevistados Asugovianos, Governador Valadares, 2019

\begin{tabular}{|c|c|c|c|}
\hline Entrevistado & Sexo & Escolaridade & Renda \\
\hline 02) 39 anos & Fem. & Médio completo & $02 \mathrm{SM}$ \\
\hline 03) 39 anos & Fem. & Fundamental completo & $01 \mathrm{SM}$ \\
\hline 04) 26 anos & Fem. & Superior completo & S/R \\
\hline 05) 21 anos & Fem. & Médio completo & $01 \mathrm{SM}$ \\
\hline 06) 24 anos & Fem. & Médio completo & $01 \mathrm{SM}$ \\
\hline 07) 71 anos & Fem. & Fundamental completo & $01 \mathrm{SM}$ \\
\hline 08) 51 anos & Masc. & Fundamental completo & $01 \mathrm{SM}$ \\
\hline 09) 51 anos & Masc. & Médio completo & $02 \mathrm{SM}$ \\
\hline 10) 58 anos & Fem. & Superior completo & S/R \\
\hline 11) 47 anos & Masc. & Médio completo & $01 \mathrm{SM}$ \\
\hline 12) 20 anos & Masc. & Médio completo & $01 \mathrm{SM}$ \\
\hline 13) 43 anos & Masc. & Fundamental incompleto & \\
\hline
\end{tabular}

Fonte: Pesquisa de campo.

\section{4- Corpus discursivo dos entrevistados}

A partir dos discursos dos participantes foram levantadas especificidades identificatórias e/ou semelhanças relacionadas a história de vida de cada um. No Quadro 02 estão registradas as informações que cada Comunicante Surdo julgou por bem compartilhar durante as entrevistas. Considerando que cada um relatou o que considerou mais relevante em sua história, não é valorizada aqui a busca por padronização no montante das informações registradas.

Quadro 02 - Especificidades dos relatos, Governador Valadares, 2019

\begin{tabular}{|l|l|}
\hline & Relato: \\
\hline 02 & Filha de pais ouvintes, esta só foi à escola após os 05 anos de idade. Por ser \\
surda e única na família com surdez os pais tinham muito medo de possíveis \\
maus-tratos por outrem ou bullyng no ambiente escolar. Quando começou a \\
frequentar a escola não existia naquele tempo língua de sinais. As tentativas
\end{tabular}




\begin{tabular}{|c|c|}
\hline & $\begin{array}{l}\text { foram no sentido de oralizá-la. Somente aos } 16 \text { anos aprendeu libras. Em casa, } \\
\text { por falta da compreensão dos familiares sobre o que é a surdez e ser surda, } \\
\text { treinou libras por muito tempo de forma escondida. }\end{array}$ \\
\hline 03 & $\begin{array}{l}\text { Filha de pais ouvintes e irmãos ouvintes. Foi muito estimulada pelos familiares } \\
\text { ao aprendizado na forma de oralização. Somente após aprender a falar é que a } \\
\text { mãe a deixou sair sozinha. A mãe tinha muito medo de que algo ruim pudesse } \\
\text { lhe acontecer. Mais especificamente temia que se tornasse alvo de abuso sexual } \\
\text { por parte de homens. }\end{array}$ \\
\hline 04 & $\begin{array}{l}\text { Filha de pais surdos, oralizada. Desde sempre tem contato com a comunidade } \\
\text { surda sinalizante. Ainda na infância aprendeu com os pais que existia dois } \\
\text { mundos a transitar: os dos ouvintes e o dos surdos. Neste sentido conversa com } \\
\text { familiares na forma oral. Dificuldades ocorreram com familiares, contudo os } \\
\text { pais a fizeram sobreviver a essas. }\end{array}$ \\
\hline 05 & $\begin{array}{l}\text { Foi adotada por uma família ouvinte e a avó foi uma pessoa marcante na vida } \\
\text { da entrevistada. Os familiares, no geral lhe davam reduzida atenção devido sua } \\
\text { condição de Pessoa Comunicante Surda. }\end{array}$ \\
\hline 06 & $\begin{array}{l}\text { A família ouvinte custou a perceber que era surda. Por conta disso foi alvo de } \\
\text { ações violentas oriunda dos próprios familiares, para que correspondesse a } \\
\text { contento como criança ouvinte. Manteve-se isolada, ao máximo que conseguiu. } \\
\text { Quando começou a estudar, ao convívio dialógico gestual, comunicava } \\
\text { conforme entendia. Era em uma escola estadual para ouvintes e inclusiva. }\end{array}$ \\
\hline 07 & $\begin{array}{l}\text { A família ouvinte, quando percebeu que ela ouvia muito pouco de um ouvido, e } \\
\text { com o tempo a surdez total seria inevitável, a internou em um espaço o qual } \\
\text { tratava pessoas com doenças mentais. A entrevistada contava com } 16 \text { anos } \\
\text { nessa época. Foi um período muito ruim, pois a entrevistada não entendia o que } \\
\text { estava fazendo ali. Via todo mundo com deficiência e ela sentia que aquele não } \\
\text { deveria ser seu lugar. }\end{array}$ \\
\hline 08 & $\begin{array}{l}\text { O entrevistado começa relatando sobre como é difícil ser surdo. Tenta conversar } \\
\text { com a família (ouvinte), mas ser surdo é muito difícil. Não consegue comunicar } \\
\text { com ninguém, então deixa a conversa prá lá. No serviço também é assim e por } \\
\text { isso participa da associação dos surdos porque é muito melhor. A esposa é surda }\end{array}$ \\
\hline
\end{tabular}




\begin{tabular}{|c|c|}
\hline & a. \\
\hline 09 & $\begin{array}{l}\text { Pais estrangeiros e ouvintes. Considera ser surdo uma situação muito difícil e } \\
\text { angustiante para se comunicar. Somente aos } 05 \text { anos de idade conseguiu } \\
\text { locomover-se após muita fisioterapia. Teve muita dificuldade na escola para } \\
\text { com o aprendizado por causa principalmente da função motora que não } \\
\text { dominava. Sempre quis aprender muito e no início pensava que era ouvinte } \\
\text { também. A mãe foi quem percebeu que ele não comunicava. Foi através de } \\
\text { outro surdo associado a Asugov que conheceu libras. A Igreja Católica também } \\
\text { foi um lugar de aprendizado. }\end{array}$ \\
\hline 10 & $\begin{array}{l}\text { Filha de pais ouvintes. Estudou em escola especializada em Belo Horizonte até } \\
\text { os } 15 \text { anos. Retornando para Governador Valadares estudou em uma escola } \\
\text { inclusiva, mas considera este período escolar muito difícil devido a falta de } \\
\text { prepara dos educadores. Aos } 19 \text { anos voltou para Belo Horizonte, escola } \\
\text { especializada com fonoaudiólogo e aprendeu a falar (oralizada). Retornou a } \\
\text { Governador Valadares e teve vontade de parar com os estudos. Trabalhava em } \\
\text { uma loja de roupas e aos } 26 \text { anos casou-se com um Sujeito Comunicante Surdo. }\end{array}$ \\
\hline 11 & $\begin{array}{l}\text { Família ouvinte revelou que encontra muita dificuldade, barreiras, limitações } \\
\text { em ser admitido em um trabalho. Relata ser muito difícil ser Sujeito } \\
\text { Comunicante Surdo. }\end{array}$ \\
\hline 12 & $\begin{array}{l}\text { Filho de pais ouvintes, o entrevistado trabalha na oficina mecânica com o pai. } \\
\text { Considera a convivência entre surdos e ouvintes na associação como ponto } \\
\text { positivo. Como negativo a falta conversas com os ouvintes na rua e em outros } \\
\text { lugares de convivência. Por isso nem conversa. }\end{array}$ \\
\hline 13 & $\begin{array}{l}\text { Filho de pais ouvintes mora sozinho em residência dos pais. Os pais, ouvintes, } \\
\text { foram morar em Florianópolis e o irmão, ouvinte, é imigrante nos EUA. Por } \\
\text { conta da baixa visão deixou os estudos. Relatou que comunicar, conversar com } \\
\text { surdos e/ou ouvintes é muito difícil. Por isso fica na dele sempre. }\end{array}$ \\
\hline
\end{tabular}

Fonte: Pesquisa de campo.

\section{5- Rede social Facebook Asugov GV}


Recuero (2012) contribui ao nosso dialogo ao afirmar que espaços interacionais mediados por tecnologias, adquirem contornos similares aqueles da conversação 'face a face', visando estabelecer e/ou manter laços sociais, ao escopo de apropriação ao exercício do direito de comunicação. A internet atual também conhecida como web 2.0 tem como principal característica a possibilidade de sociabilização entre pessoas e grupos por meio de plataformas de comunicação mediadas por computador. Essas deixam rastros, os quais por sua vez, podemse nominar redes sociais. O Facebook, rede social de nosso interesse, é descrito como um produto/serviço que tem como missão 'dar as pessoas o poder de criar comunidades e aproximar as pessoas' (KIRKPATRICK, 2011), compartilhando e expressando o que as mesmas pensam ser importante para elas. Sob este ângulo de percepção a ser rastreada, exercício do direito de comunicação, vale a pena apresentar os atores participantes observados, possuidores de perfis na rede social Facebook:

- Participante Asugov GV - gênero feminino, entidade, tem sua pagina no facebook desde junho 2018. Perfil aberto. Possui 03 mil amigos associados em sua rede. Apresenta como foto de perfil o atual logotipo da Asugov sobreposto a foto da capa onde faz constar a mesma imagem.

- Participante 03 - gênero feminino, superior completo em Ciências Contábeis e atualmente cursa Letras Libras. 26 anos. Solteira, trabalha em um escritório prestador de serviço de internet. Recebe 02 salários mínimos. Católica e participante da pastoral dos surdos. Possui cargo eletivo na atual administração da Asugov. Professora de Libras. Tem sua pagina no Facebook desde março de 2019. Nesta faz constar o nome civil completo e deixa público algumas informações a seu respeito, tais como: informações educacionais, lugares onde morou, informações básicas e de contato através de e-mail, informações sobre relacionamento e membros de sua família (todos com fotos), e apelido. Possui mais de 02 mil amigos associados em sua rede.

- Participante 05 - gênero feminino, ensino médio completo. 24 anos. Solteira, na entrevista disse não exercer função laboral remunerada. Recebe auxilio/beneficio governamental. Não possui cargo eletivo na atual administração da Asugov. Tem sua pagina no Facebook desde setembro de 2011. Nesta faz constar o nome civil completo e uns dizeres atribuídos a William Shakespeare. Deixa públicas algumas informações a seu respeito, tais como: ter profissão de cabelereira desde 2013 até o 
presente momento, informações educacionais, lugares onde morou, informações básicas e de contato através do Instagram, informações sobre relacionamento, e em detalhes reforça citações bíblicas. Possui poucos amigos associados em sua rede.

- Participante 11 - gênero masculino, ensino médio incompleto. 20 anos. Solteiro, trabalha com o pai em uma oficina mecânica, recebendo entorno de 01 salario mínimo. Tem sua pagina no Facebook desde 2018. Possui mais de 630 amigos associados em sua rede. Nesta faz constar o nome civil incompleto e deixa público algumas informações a seu respeito, tais como: informações educacionais, lugares onde morou, não informa contato, nenhuma informações sobre relacionamento e membros de sua família.

Hoje na chamada sociedade da informação, os usos dos meios e seus recursos, possibilitam ao individuo ter acesso informacional a complexidades de contextos tanto próximos como distantes de sua realidade o qual, num processo construtivo, pode servir como elemento educativo, de aprendizagem, como espaço de socialização, reivindicação, exercício de direitos, gerando saberes e sentidos. Não apresento aqui consenso nem discussão sobre o que caracterizaria ou distinguiria os usos e seus sentidos. Tento demarcar nuances que possam indicar singularidades observadas. E, ao voltarmos nossos olhares para os usos realizados no Facebook da associação e dos nossos colaboradores, indicamos em uma primeira visada que esses usos não se constituíram apenas como uma ferramenta ou um recurso para o estabelecimento de novas amizades, e sim, para a manutenção das existentes, propiciando desta forma um espaço relacional para exposição de suas identidades e subjetividades. Um sentido possível de se apontar para com esse uso foi à manifestação de ideias, o que sentem, desejam, servindo-se desse lócus para representarem-se como indivíduos únicos, plurais, exercentes dos seus direitos, em uma sociedade conectada, revelando-se como vitrines de produtos e produtores que transformam e são transformados na medida em que compartilham, postam e relevam seus gostos, preferências, culturas, ideologias, filosofias de vida, as quais são transmitidas e fluem entre as interações na mídia social. (EMEDIATO, 2015).

\section{6- Colóquio reflexivo a guisa de discussão dos resultados}


De partida deve-se registrar que as observações refletidas nas respostas dos entrevistados, foram fundamentadas na Teoria das Representações Sociais (TRS) em uma perspectiva da construção histórica-social-antropológica acerca da cultura surda, para assim, quem sabe, não incorrermos em perversidades históricas. A Teoria das Representações Sociais elaborada por Moscovici, em 1961, é apresentada como uma teoria que proporciona o entendimento dos processos de elaboração coletiva sobre um dado objeto social, objeto este viabilizado por meio da troca de informações e da produção coletiva de saberes pelos grupos sociais. Neste sentido, vale reproduzir as próprias palavras do autor: “[...] modalidade de conhecimento particular que tem por função a elaboração de comportamentos e a comunicação entre indivíduos" (MOSCOVICI, 2007, p. 32-46).

Nessas duas particularidades, elaboração de comportamentos e a comunicação entre indivíduos, em diálogo com Moscovici, pode-se afirmar que as Representações Sociais (RS) permitem que as pessoas dominem seu mundo materialmente (em relação ao objeto/coisa) e socialmente (em relação ao outro) principalmente pelo viés comunicacional. Destarte, Moscovici (2007) ao descrever representações como sendo 'um meio de troca' e 'instrumentos de troca' permite que um grupo coordene em relação ao objeto dado, RS para estabelecer ou reforçar no grupo identidade e história.

Desta forma, e vivendo em um mundo totalmente social, as RS são alimentadas por conhecimentos oriundos de uma predisposição genética herdada, por imagens e hábitos apre(e)ndidos, por recordações preservadas, por categorias culturais estabelecidas, organizadas por uma determinada sequência de natureza convencional e prescritiva, atribuindo sentido ao mundo, constituindo-se em saberes práticos produzidos nas interações sociais, conferindo sentido aos comportamentos estabelecidos nos processos comunicacionais (MOSCOVICI, 2017).

As RS devem ser vistas como uma maneira específica de compreender e comunicar. Através dessas ações, compreender e comunicar objetiva abstrair sentido do mundo e introduzir nele ordem e percepções que reproduzam o mundo de uma forma significativa. Essas estruturam saberes cotidianos, teorias populares, senso comum, enfim, tudo o que resulta do conhecimento prático orientado para a compreensão do mundo e para a comunicação entre os indivíduos (SILVA, 2018). Silva ainda nos permite refletir sobre as chamadas RS e seu perpasse para a representação social da surdez nos dizeres:

São representações que se elaboram na construção cognitiva, investida de afeto, da realidade social. São imagens, mitos, valores, significados contemporâneos 
construídos pelos sujeitos a respeito dos objetos socialmente valorizados. Envolvem comunicação e discurso, determinam a relação do sujeito com o outro, pois o indivíduo se estrutura a partir das representações sociais de seu grupo e da sua comunidade. Torna-se, assim, sujeito de seu tempo e, nesta relação, estrutura, também, num processo interativo, novas representações (SILVA, 2018, p. 115).

Neste diapasão, pode-se afirmar que as RS acerca da surdez foram formadas a partir de uma herança histórico-cultural da sociedade ouvinte, na interação das relações cotidianas do sujeito surdo com o objeto social eleito como normal: o ser ouvinte.

Metaforicamente, acrescemos a imagem do que sejam RS, à imagem de uma moeda possuindo duas faces interdependentes: a face icônica (moeda) e a face simbólica (significação). Duas faces: mão dupla entre o percurso de ir e vir, entre sujeito e mundo, um construir como objetos sociais. Construção, possível e partilhável, fundamentada em bases na realidade social. Pedrinho Guareschi (1997, p. 218) em uma interlocução sobre a realidade social, e sobre a representação social a acerca da surdez, argumenta: “As representações sociais são uma constante construção: elas são realidades dinâmicas e não estáticas. Vão sendo reelaboradas e modificadas dia a dia. Vão sendo ampliadas, enriquecidas com novos elementos e relações".

Novas relações e elementos construtores podem ser observados no contexto dos relatos dos participantes. A essa, buscamos significar cultura. Quanto ao conceito de cultura de forma verticalizada em seu significado, Muniz Sodré assim o esclarece: "Conjunto das relações de sentido (atualizadas em comportamentos, normas, valores) presentes em todas as instâncias de uma formação social” (1984, p. 119). Nesse sentido pode-se pensar que cultura se constitui nos processos de diálogo e que este diálogo se realiza, também, nas relações estabelecidas sob características diversas da sociedade hodierna.

Claudio (2016) aborda cultura a partir do ponto de vista do sujeito, ator social, elemento humano construtor da cultura. Pensa a identificação do humano com o próprio identificado, em seus valores, direitos, costumes, línguas e crenças. Neste sentido afirma:

[...] podemos dizer que a cultura é a base sobre a qual a subjetividade do indivíduo está defendida, em primeiro lugar, pelo reconhecimento na própria pessoa. Isso quer dizer que os sujeitos comunicantes surdos, nos grupos sociais, podem possuir interesses diferentes, por exemplo, lutas e direitos em comum, e buscam sua identificação no pertencimento à comunidade surda (CLAUDIO, 2016, p. 91). 
Na concepção da pesquisadora Karin Strobel (2018) a cultura surda, sob a ótica de quem vive a surdez, é um convite a conhecermos o que é cultura surda e repensarmos os olhares e as imagens que construímos sobre os surdos:

Cultura surda é o jeito de o sujeito entender o mundo e de modificá-lo a fim de tornálo acessível e habitável, ajustando-o com suas percepções visuais, que contribuem para a definição das identidades surdas e das "almas" das comunidades surdas. Isto significa que abrange a língua, as ideias, as crenças, os costumes e os hábitos do povo surdo (STROBEL, 2018, p. 29).

Karnopp, Klein e Lunardi-Lazzarin (2011) dialogam conosco no sentido de que cultura é o que é produzido pelo ser humano, distinto das coisas dadas; natural, existente no mundo. Desta forma, argumentam que a concepção de cultura em oposição à natureza repercutia na forma como os sujeitos e grupos surdos foram narrados e tratados pelas instituições ao longo da história. Esta lhes negou possibilidades de inscrição de suas narrativas como grupo cultural, capaz de produzir significados a partir de suas experiências compartilhadas. Vale trazer as observações dessas autoras como forma dialógica e consubstanciadora aos nossos pensamentos:

\begin{abstract}
A partir da estreita relação que o contexto histórico pode estabelecer com o movimento surdo, gostaríamos de ressaltar que, ao percorrermos alguns fragmentos da história do movimento surdo, percebemos também essa ligação. Em outras palavras, enquanto a Língua Brasileira de Sinais (LIBRAS) não era reconhecida ou enquanto era proibida de ser usada nas escolas e em diferentes espaços sociais, também não existiam publicações ou o reconhecimento da Cultura Surda. O ensino priorizava o aprendizado da fala e da língua portuguesa. Nas escolas, não havia espaço nem aceitação para as produções culturais em sinais. No entanto, entre os surdos circulavam histórias sinalizadas, piadas, poemas, histórias de vida, mas em espaços que ficavam longe do controle daqueles que desprestigiavam a língua de sinais. Especificamente no panorama brasileiro, é possível constatar ainda que para muitas pessoas torna-se irrelevante e, para outras, decisivamente incômoda, a referência a uma cultura surda. (KARNOPP, KLEIN, LUNARDI-LAZZARIN; 2011, p. 18).
\end{abstract}

As referências para com a cultura surda são sinonímias das representações, sobre as quais o significado não se encontra no texto/relato, mas na relação entre o texto/relato e o contexto dos participantes da pesquisa. Considerar o contexto compartilhado dos entrevistados, a associação Asugov, rede social Facebook Asugov GV revela de perto que não é suficiente concebê-los simplesmente como simples espaços físico e ou virtual, de encontros, mas sim espaços de empoderamentos e encontros entre os seus. Considerar o contexto compartilhado dos entrevistados acerca das questões família e comunidade torna-se imperioso reconhecer a perversidade do reforço à diferença, ao domínio da cultura ouvinte, o que acarreta sim, a 
perpetuidade de 'coisa ruim', de se ser surdo. O contexto religiosidade surge como um pequeno balsamo nas representatividades perversas do colonizador ouvinte dominante.

Neste contorno material, substantivo, com nuances tristes e balsâmicas, o meio comunicacional ofertado nas TICs, em especificidade as redes sociais, oferta ao sujeito surdo um ultrapasse daqueles contornos, conectando-se ao mundo digital, em uma diversidade de informações e de pessoas, em sendo mais, sem sofrer qualquer tipo de discriminação por ser surdo. Nessa esfera de realidade virtual conquista e exerce o direito comunicacional de forma igualitária, no mundo hegemônico ouvinte, de forma a consubstanciar as chamadas civilidades. Desta forma, a cidadania apresenta-se como arcabouço das civilidades, pilar da sociedade civil, em interesses os quais inclui-se as exigências para com o convívio dos diferentes grupos sociais, a chamada cidadania multicultural. Neste contexto deve-se entender que a cidadania é uma propriedade humana, resultante de uma prática educacional formal (escola) e informal (família, amigos, meios de comunicação, ambiente social) (CORTINA, 2005).

Neste olhar, Mata corrobora com nossos pensamentos acerca de cidadania como arcabouço de civilidades, apontando como condições subjetivas da mesma "[...] aos significados compartilhados pelos integrantes da sociedade acerca dos direitos à informação e à comunicação" (MATA, 2005, p. 3), ou seja, às forças geradoras de inquietações, motivações e expectativas e que movimentam os sujeitos para a prática da cidadania comunicativa.

\section{CONSIDERAÇOES FINAIS TRANSITORIAS}

Os escritos apresentados encontram-se entrelaçados a trajetória de uma tese de doutoramento, em construção, marcada por desafios que dialogam transdisciplinarmente com questões teóricas do campo comunicacional e do direito. Contudo, no contexto dos relatos dos participantes entrevistados, a elaboração de comportamentos e a comunicação entre indivíduos, via de regra, foram marcados pelos sentimentos de medo, de possíveis maus tratos, abusos. Nessa particularidade, a elaboração de comportamentos e a comunicação entre indivíduos, surdos e/ou ouvintes, permitiu e ainda permite que as pessoas que dominam seu mundo materialmente (em relação ao objeto/coisa) e socialmente (em relação ao outro), principalmente pelo viés comunicacional, alimentam ainda neste século RS negativas sobre surdez. Permitem 
assim, negar a possibilidade desses atores sociais como grupo social cultural, capaz de compartilhar experiências significativas. As RS por serem realidades dinâmicas, reelaboradas e modificadas dia a dia, deixa no dialogo observado dos comunicantes surdos entrevistados, um alento transparecer nas ações comunicacionais ampliadas e enriquecidas, obtidas nas relações encontradas nos campos religiosos. O campo virtual ultrapassa as RS negativas, incipientemente, e caminha a erigir-se nas mídias digitais, em especial no Facebook, em suas praticas relacionais sociais, novos tempos, civilidades, novos cidadãos; um exercício eficaz e efetivo a erigir a cidadania comunicativa desse grupo populacional.

Os atravessamentos alcançados através do uso da rede social podem ser percebidos nas possibilidades infinitas das praticas comunicacionais realizadas, praticas essas que os perfis observados atribuíram nas publicações e interações realizadas naquele espaço virtual, afirmando suas identidades, subjetividades, pensamento, visão de mundo, preferencias, escolhas. Todas apresentadas e representadas nas publicações, postagens, curtidas, compartilhamentos. A essas, passo a denominar 'ecos das personas'. Eco é um reflexo do som, ondas modulares. E, através desse sentido metafórico, pertinente o é, apontar que a maioria das praticas comunicacionais se elucubram através de modulações propostas por algoritmo. Esses ao detectarem conteúdos que chegam dos participantes (perfis), selecionam as mensagens em conformidade com as interações estabelecidas, direcionando a uma construção ao consumo cultural. Assim, estabelecem-se consumidores, mesmo que no âmbito da cultura, e não cidadãos. E como consumidores, esses mecanismos de usos, alcançados por algoritmos, apropriados pelos usuários estão de alguma forma a impactar ideias, valores, gostos, comportamentos dentro e fora do ciberespaço.

\section{REFERENCIAS}

BRAGA, A. Técnica etnográfica aplicada à comunicação online: uma discussão metodológica. UNIrevista, v.1, n.3, jul. 2006.

CLÁUDIO, J. P. A cultura dos sujeitos comunicantes surdos: construções da cidadania comunicativa e comunicacional digital no facebook/ por Janína pereira Claúdio. - 2016. 239 f.: 
il,30cm. Tese (Doutorado) - Universidade do Vale do Rio dos Sinos, Programa de Pósgraduação em Ciências da Comunicação, 2016. Orientação; Prof. Dr. Alberto efendy Maldonado Gómez de la Torre. Disponível em: http://www.repositorio.jesuita.org.br/bitstream/handle/UNISINOS/6044/Jana\%C3\%ADna+Per eira+Claudio_.pdf?sequence=1 Acesso em outubro de 2019.

CORTINA, Adela. Cidadãos do mundo para uma teoria da cidadania. SP: São Paulo, Edições Loyola, 2005.

EMEDIATO, Wander. Discurso e Web: As múltiplas faces do Facebook. (C Revista da ABRALIN, v.14, n.2, p. 171-192, jul./dez. 2015. Disponivel em. Acesso em 20 de abril de 2020.

FOLETTO, Rafael. Na trilha de Fernando Lugo: construindo processualidades metodológicas para investigar as representações do presidente paraguaio nas revistas semanais brasileiras. Metodologias de pesquisa em comunicação: olhares, trilhas e processos. Editora Sulina: Porto Alegre/RS, 2011.

JODELET, D. Representação Sociais: um domínio em expansão. (2001). In: As Representações Sociais. Tradução: Lilian Ulup. Rio de Janeiro: EDUERJ. 2001.

Representações sociais e mundos de vida. Edição de Nikos Kalampalikis. PUCPRESS, 2017.

KARNOPP, KLEIN, LUNARDI-LAZZARIN. Compartilhando significados culturais: produção, circulação e consumo da cultura surda e a constituição de identidades surdas. VII Congresso Português de Sociologia; Universidade do Porto, junho de 2012.

KOZINET, Robert V. Netnografia: Realizando Pesquisa Etnografica online. Tradução Daniel Bueno; revisão técnica: Tatiana Melani Tosi, Raul Ranauro Javales Junior. Dados eletrônicos. Porto Alegre: Penso, edição digital, 2014.

LEVI, Pierre. O que é o virtual? São Paulo, Editora 34, 1996.

MALDONADO, E. Epistemologia, investigação e formação científica em comunicação. In: (ORG), E. A. A transmetodologia no contexto latino-americano. Rio do Sul: UNIDAVI, 2012.

MATA, Maria Cristina. Condiciones objetivas y subjetivas para el desarrollo de la ciudadania comunicativa. Córdoba: Centro de Competência en Comunicación para América Latina, 2005.

MOSCOVICI, Serge. Representações Sociais - Investigação em psicologia social. Petrópolis: Vozes, 2007. ISBN: 978-85-326-2896-1.

MUNIZ SODRÉ. O monopólio da fala (Função e linguagem da televisão no Brasil). Petrópolis, Vozes, 1984. 156 p. 
NOVELLI, M. Do off-line para o on-line: a Netnografia como um Método de Pesquisa ou o que pode acontecer quando tentamos levar a Etnografia para a Internet? Organizações em Contexto, v. 6, n. 12, p. 107-133, 2010.

ROCHA, E. P. QUIMARÃES; BARROS, C.; PEREIRA, C. Perspectivas do método etnográfico em marketing: consumo, comunicação e netnografia. In: ENANPAD, 24, 2005, Brasília. Anais... Brasília: ANPAD, 2005.

ROCHA, E.; BARROS, C.; PEREIRA, C. S. Do ponto de vista nativo: Compreendendo o consumidor através da visão etnográfica. In: Encontro dos Núcleos de Pesquisa da Intercom, 5, 2007, Anais... São Paulo: Intercom, 2007.

SILVA, Angela Carrancho da. Aprendendo a ouvir o silêncio. In: SILVA, Angela Carrancho da Silva e NEMBRI, Armando Guimarães. Ouvindo o silêncio - surdez, linguagem e educação. Porto Alegre: Mediação, 2018; p.113-126. ISBN: 978-85-7706-027-6.

STROBEL, K. As imagens do outro sobre a cultura surda. Florianópolis: editora UFSC, 2013. $4^{\mathrm{a}}$ edição. $1^{\mathrm{a}}$ reimpressão. 2018. 146 págs. ISBN 978-85-328-0778-6. 